\title{
DERECHO Y CONSUMO. ASPECTOS PENALES, CIVILES Y
} ADMINISTRATIVOS, Lorenzo Morillas Cueva (Dir.) y José María Suárez López (Coord.), Dykinson, Madrid, 2013.

\author{
Por Samuel Rodríguez Ferrández. \\ Profesor Ayudante Doctor de Derecho Penal \\ Universidad de Murcia \\ samuel.rodriguez@um.es
}

La presente obra es el resultado de una profunda labor investigadora llevada a cabo en el marco del Proyecto de Investigación (DER2009/12717) "La protección penal del consumidor", financiado por el Ministerio de Ciencia e Innovación y dirigido por el Prof. Dr. H. C. Mult. D. Lorenzo Morillas Cueva, Catedrático de Derecho Penal en la Universidad de Granada, en la que han participado profesores universitarios, pertenecientes a distintas áreas de conocimiento, de las Universidades de Granada, Jaén, Almería, Murcia, Alicante y Sevilla, constituyendo la multidisciplinariedad temática (así como de autores) uno de los principales atractivos de la obra, en tanto no se trata de una publicación al uso, donde se aborde el objeto de estudio desde un prisma exclusivamente jurídico desde un área concreta, sino que se analizan exhaustivamente las principales cuestiones vinculadas a la protección de los consumidores desde distintos parámetros y enfoques jurídicos vinculados al campo del Derecho Penal, Civil, Administrativo, Historia del Derecho, encontrando el lector, sin ningún género de dudas, respuestas a todos los interrogantes que pudieran surgirle respecto a la temática tratada.

En efecto, este libro colectivo es uno de los resultados del mencionado proyecto que, pese al tenor literal de su título oficial anteriormente transcrito, y como aparece reflejado en el título de esta obra, abordó en realidad el estudio y análisis de prácticamente todos los perfiles y enfoques que se pueden presentar en la protección jurídica de los consumidores a lo largo de veintitrés capítulos estructurados en seis partes o bloques temáticos diferentes. 
Así, resulta que en este libro colectivo se analizan los principales problemas jurídicos, (fundamentalmente los penales, claro está, porque la mayor parte de los investigadores se encuentran adscritos a este área de conocimiento), que surgen en la protección del consumidor, en lo que constituye un estudio profundo y multidisciplinar. Más en detalle, como aportaciones generales de este estudio colectivo se pueden identificar las siguientes:

- en primer lugar, se han evaluado los principales problemas que surgen en el propio ámbito de protección penal de los consumidores, lo cual ha obligado al grupo de investigación a incluir también en la obra el estudio de las consecuencias jurídicas previstas en otros ámbitos como el administrativo y civil y en qué medida son adecuadas;

- en segundo lugar se analizan pormenorizadamente las cuestiones dogmáticas y de Política criminal de las herramientas jurídicas disponibles y su compatibilidad con los principios limitadores del "ius puniendi" de un Estado social y democrático de Derecho;

- en tercer lugar, y en línea con los niveles de especialización del equipo de trabajo que ha participado en la obra (compuesto, además de penalistas, por civilistas, administrativistas e historiadores del Derecho), se ha profundizado en el análisis de la responsabilidad civil por los daños ocasionados a los consumidores y la responsabilidad sancionadora que prevé el Derecho administrativo sancionador y todo ello, sin perder de vista los niveles de eficacia que se han obtenido en los diversos tratamientos legales que se han empleado para tutelar al consumidor.

En definitiva, el propósito que impregna toda la obra es el de permitir ofrecer soluciones a las principales dificultades existentes en la protección jurídica de los consumidores, con relevantes propuestas "de lege lata" y "de lege ferenda", al mismo tiempo que crear un eficaz sistema de tutela del mismo. 
En lo que se refiere a las aportaciones concretas o particulares del libro, iremos haciendo referencia a las mismas detallando el contenido de cada bloque o parte en sus diferentes Capítulos.

Puestos a ello, la "Parte I" se dedica a "Cuestiones generales" y viene compuesta por un único Capítulo, en el cual, titulado "De la autonomía de la voluntad al imperativo estatal en la protección de consumidores en España. Un estudio histórico-jurídico", Antonio Sánchez Aranda realiza un estudio en el que expone tanto los inicios de la protección de los consumidores en la legislación española, como una visión de la constitucionalización de tal protección, con la subsiguiente promulgación de la Ley General para la Defensa de los Consumidores de 1984.

La "Parte II" comienza con el estudio de las cuestiones jurídico-penales de la protección de los derechos de los consumidores y, en concreto, con las relativas a la Parte general. Así, el Capítulo II, titulado "Delimitación conceptual y legitimidad de la intervención penal" y realizado por Javier Valls Prieto, introduce al lector en los parámetros generales de la tutela penal de los consumidores y usuarios en nuestro Ordenamiento, distinguiendo este ámbito del administrativo sancionador, y señalando cuáles son los bienes jurídicos protegidos. Complementando esta introducción, aparece el Capítulo III, bajo el título "La proyección penal de los principios limitadores del ius puniendi de un Estado social y democrático de Derecho en la protección penal del consumidor" de José María Suárez López, señalando los de legalidad, intervención mínima y "non bis in idem" como los más destacados en esta materia. El Capítulo IV, elaborado por Lorenzo Morillas Cueva, sin dejar todavía los parámetros generales de la tutela penal, empieza a concretar un ámbito de la protección de los consumidores con el estudio de un tema discutido desde hace años por nuestras doctrina y jurisprudencia, cual es el de "Los intereses de los consumidores como bien jurídico en los delitos relativos a la propiedad industrial. Especial consideración a los signos distintivos". Finalmente, el Capítulo V se centra en una cuestión, todavía genérica, pero referida al ámbito procesal, al estudiar Jesús Martínez Ruiz "La competencia de la audiencia nacional de los delitos contra los consumidores. La necesaria revitalización del principio de taxatividad en el proceso penal". 
El Capítulo VI da inicio al análisis de los tipos penales existentes para la protección de los consumidores y usuarios (Parte III), y lo hace con la exposición inicial de todo el panorama sistemático del Código Penal en esta materia, por parte de Fátima Pérez Ferrer y bajo el título "Aspectos dogmáticos y político-criminales de la protección del mercado, la competencia y los consumidores en el derecho penal español". Así, se suceden a partir de este momento los estudios exegéticos de los delitos diseminados a lo largo del Código penal para la protección, directa o indirectamente, de los derechos e intereses de los consumidores: el primero de los tipos penales estudiados es "El delito de publicidad engañosa", que, incardinado en el Capítulo VII, corre a cargo de Belén Macías Espejo; el segundo de los delitos que se estudian en esta parte de la obra es, en el Capítulo VIII, "El delito de facturación abusiva", por parte de María José Jiménez Díaz; en tercer lugar, y en el Capítulo IX, Ignacio Lledó Benito, que se encuentra preparando su tesis doctoral sobre este tema, afronta el estudio de "La estafa de inversores en relación con el delito de publicidad engañosa"; Pilar Fernández Pantoja analiza pormenorizadamente "El delito de maquinaciones para alterar el precio de las cosas" a lo largo de las páginas del Capítulo X; con buen criterio se ha incluido también en esta parte de la obra el análisis de "El delito farmacológico del artículo 361 del Código Penal", que corre a cargo de Nuria Castelló Nicás; también son objeto de estudio "Los fraudes alimentarios nocivos realizados por productores, distribuidores y comerciantes", bajo la autoría de Ignacio Francisco Benítez Ortúzar y en el Capítulo XII; complementariamente, Eva $\mathrm{M}^{\mathrm{a}}$ Domínguez Izquierdo expone en el Capítulo XIII los perfiles jurídico-penales de "La adulteración de productos alimentarios y la alimentación del ganado con sustancias no permitidas"; y, para finalizar esta parte, la más extensa de la obra, María José Cruz Blanca aborda el análisis de la "Responsabilidad penal por la adulteración o envenenamiento de aguas potables y alimentos destinados al consumo humano" en el Capítulo XIV.

Es de destacar la original y acertada inclusión, siguiendo la estructura de bloque temático "unicapitular" (bajo la rúbrica "Criminología"), de un interesante estudio, en el Capítulo XV, sobre la "Delimitación del sujeto activo desde el ámbito criminológico" en "Los delitos relativos al mercado y a los consumidores", realizado por Marta María Aguilar Cárceles, psicóloga, criminóloga y jurista de la Universidad de Murcia. 
Tras él, comienza la quinta parte o bloque, integrado por los dos estudios que abordan la protección de los derechos de los consumidores en el ámbito del Derecho administrativo. Así, Ramón Terol Gómez desmenuza en el Capítulo XVI cuál es en la actualidad "El régimen sancionador en materia del consumo", estudiando "Las disposiciones del Real Decreto Legislativo 1/2007, de 16 de noviembre, por el que se aprueba el texto refundido de la ley general para la defensa de los consumidores y usuarios". Y para cerrar esta parte de la obra, Salvador Ma Martín Valdivia introduce en el Capítulo XVII unas reflexiones generales bajo el título "El Derecho administrativo sancionador en materia de consumo. De sarcasmos y aporías", trabajo en el que analiza algunos de los problemas jurídico-interpretativos de tal regulación, como el riesgo de la vulneración del principio "non bis in idem" por el exceso tipificador, la indefinición de las cláusulas de cierre o la ausencia de graduación de las infracciones.

La parte reservada en el libro a la protección de los derechos de los consumidores y usuarios por parte del Derecho civil, comienza con el trabajo de Ramón Herrera Campos, dedicado, en el Capítulo XVIII, a la exposición de "La regulación del arbitraje de consumo", con especial interés en los órganos intervinientes y en los actos jurídicos esenciales del mismo. A continuación, Guillermo Orozco Pardo complementa el anterior trabajo con su estudio, ubicado en el Capítulo XIX, sobre "La mediación en los conflictos de consumo", en el que tiene especial interés el análisis del procedimiento y la fuerza vinculante del eventual acuerdo que ponga fin al mismo. En el Capítulo XX Ramón Herrera de las Heras realiza un análisis legislativo de "La protección de los consumidores en el servicio de reparaciones a domicilio", materia en la que tiene especial trascendencia la normativa de las Comunidades Autónomas. Muy específico e interesante es el estudio que Marta Morillas Fernández realiza en el Capítulo XXI sobre "El menor como consumidor y su protección ante la publicidad televisiva". El penúltimo capítulo de la obra, el XXII, lo centra Eduardo de la Iglesia Prados en el estudio (muy exhaustivo) de una norma comunitaria, cual es "La Directiva 2011/83/UE de protección de los consumidores y su incidencia en el ordenamiento español". Y, por último, la obra culmina con el Capítulo XXIII, que afronta la exposición de un tema extremadamente actual, cual es "La protección de los consumidores y las técnicas empresariales de marketing 2.0", por parte de Miguel Ángel Moreno Navarrete. 
En definitiva, nos encontramos ante una obra extraordinariamente completa, de gran interés por ello, no sólo para cualquier investigador que quiera aproximarse al estudio de la protección jurídica de los derechos e intereses de los consumidores, sino también para los juristas prácticos que precisen de una herramienta de consulta de gran utilidad sobre la materia. 